\title{
Guanine: A Combined Study Using Vibrational Spectroscopy and Theoretical Methods
}

\author{
R. Pedro Lopes, ${ }^{1}$ M. Paula M. Marques, ${ }^{1,2}$ Rosendo Valero, ${ }^{1}$ \\ John Tomkinson, ${ }^{3}$ and Luís A. E. Batista de Carvalho ${ }^{1}$ \\ ${ }^{1}$ Research Unit "Molecular Physical-Chemistry", Department of Chemistry, \\ Faculty of Science and Technology, University of Coimbra, 3004-535 Coimbra, Portugal \\ ${ }^{2}$ Department of Life Sciences, University of Coimbra, 3001-401 Coimbra, Portugal \\ ${ }^{3}$ ISIS Facility, The Rutherford Appleton Laboratory, Chilton, Didcot OX11 OQX, UK
}

Correspondence should be addressed to Luís A. E. Batista de Carvalho, labc@ci.uc.pt

Copyright (C) 2012 R. Pedro Lopes et al. This is an open access article distributed under the Creative Commons Attribution License, which permits unrestricted use, distribution, and reproduction in any medium, provided the original work is properly cited.

\begin{abstract}
The present paper reports a conformational study of solid-state anhydrous guanine, using vibrational spectroscopy techniques - infrared, Raman, and inelastic neutron scattering - coupled to quantum mechanical methods at the DFT level, both for the isolated molecule and the condensed state. In both cases, the 7H-keto-amino tautomer was found to be the prevalent form, contrary to aqueous solutions and hydrated polycrystalline guanine, where the 9H-keto-amino tautomer is the most favoured species. This paper is a significant contribution for the existing spectroscopic characterization of this purine base, by unambiguously assigning its vibrational spectra.
\end{abstract}

Keywords: Guanine, infrared spectroscopy, Raman spectroscopy, INS spectroscopy, conformational analysis, DFT, Plane-Wave calculations

\section{Introduction}

Nucleic acid bases are the building blocks of the genetic code, of fundamental importance in biology. The purine bases adenine and guanine, in particular, play a major role as structural constituents of second messengers cAMP and cGMP, respectively, in addition to their presence in adenosine and guanosine nucleosides in DNA and RNA. Knowledge of the physicochemical properties of these purine bases, namely, their structural and conformational preferences, is thus essential to understand the biochemical processes in which they are involved. In recent years, there has been a growing interest in characterizing such molecules as isolated systems, with a view to obtain a detailed comparison between theory and experiment and to develop a model capable of assisting the spectroscopic study of larger systems comprising these building blocks, such as nucleotides and nucleic acids.

Understanding the conformational behavior of guanine (2-amino-1,7-dihydro-6H-purin-6-one, $\mathrm{C}_{5} \mathrm{H}_{5} \mathrm{~N}_{5} \mathrm{O}$ ) is particularly important, since this base is often involved in relevant processes such as 
mutations leading to carcinogenesis and is one of the main targets of anticancer drugs, namely, cisplatin and its analogues.

Guanine $(\mathrm{G})$ is a bicyclic molecule comprising a fused pyrimidine (Pyr)-imidazole (Im) ring system (Figure 1), that can exist in several tautomeric forms. Accurate energetic data for these species are an important issue, particularly for interpreting spectroscopic data. In fact, the most stable guanine tautomers - either in the gas phase, aqueous solution, or the solid state-are difficult to determine precisely, as some of them are very close in energy.

Modern quantum mechanical methods can provide an accuracy of about $0.48 \mathrm{kJmol}^{-1}$, but very extensive basis sets are required [1]. As many as 36 isomers have been reported for guanine (including rotamers of the enol and imino groups), with the most stable one (in the gas phase) being the 7H-ketoamino species, followed by the 9H-keto-amino tautomer [1-4] (Figure 1). Other species, such as the 9H-cis-enol-amino, 9H-trans-enol-amino, and 7H-cis-enol-amino tautomers can also be present in the gas. Aqueous solution studies suggest that guanine occurs as a complex mixture of unusual tautomeric forms, depending on the hydration degree, with the $9 \mathrm{H}$ protonation site being preferred to the $7 \mathrm{H}$ one $[5,6]$. Furthermore, hydration has been found to increase the stability of some less populated tautomers of nucleic acid bases as well as the stacking interactions in base pairs. In the solid state, guanine can exist either in the hydrated or in the anhydrous form. Interestingly, the guanine monohydrate crystal reveals a preference for the $9 \mathrm{H}$-keto-amino tautomer $[7,8]$ (as in aqueous solution), while the anhydrous base favours the $7 \mathrm{H}$-keto-amino species $[9,10]$.

Aiming at accurately determining the structural characteristics and conformational preferences of solid neutral guanine, several spectroscopic studies have been carried out for at least three decades: infrared and Raman techniques, using fully deuterated and ${ }^{15} \mathrm{~N}$-substituted polycrystalline guanine [11], as well as inelastic neutron scattering (INS) spectroscopy coupled to theoretical calculations, in the 1980s and early 1990s [12-16]. Other studies on guanine by resonance Raman, SERS, and INS spectroscopies were also reported [4, 17-20], using either semiempirical or very simplified $a b$ initio computational methodologies as compared to the sophisticated theoretical approaches available nowadays. All published work regarding the structural and spectroscopic study of guanine has been based on the assumption that the $9 \mathrm{H}$-keto-amino form is the most stable tautomer in the solid state, which is only true for the polycrystalline guanine monohydrate form $[9,10]$. The present lack of information on the tautomeric equilibrium of anhydrous guanine may be explained by the fact that an exact knowledge on its ground and electronically excited states has not been obtained until recently, allowing to begin to understand the guanine tautomer puzzle [21]. Furthermore, the crystallographic structure of anhydrous guanine has only been reported in 2006, unequivocally showing the preference for the 7H-keto-amino tautomer over the $9 \mathrm{H}$-keto-amino one [9]. However, to this date no simulations on the condensed phase have been performed for this nucleobase, in spite of the wealth of information that can be retrieved from periodic density functional calculations (such as the Plane-Wave approach).

The use of vibrational spectroscopy-infrared, Raman, and INS-is a reliable and accurate procedure for this kind of studies, since it allows analysis of samples in both the solid state and the solution, for distinct conditions (e.g., $\mathrm{pH}$ and temperature) and in a wide concentration range. INS, in particular, is a well-suited technique to the study of hydrogenous compounds such as the nucleic acid bases. Actually, the neutron scattering cross-section of an atom $(\sigma)$ is characteristic of that atom and independent of its chemical environment. Since the value for hydrogen ( 80 barns) far exceeds that of all other elements (typically $c a$. 5 barns), the modes of significant hydrogen displacement $\left(u_{i}\right)$ dominate 


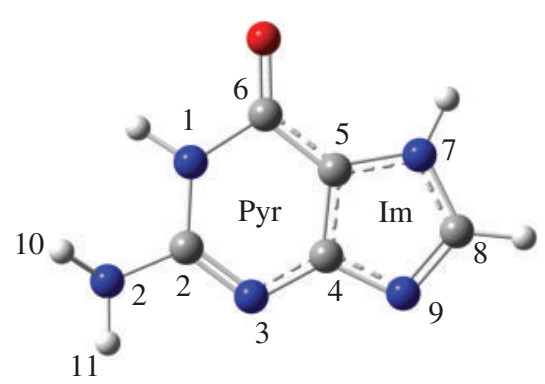

7H-keto-amino

(a)

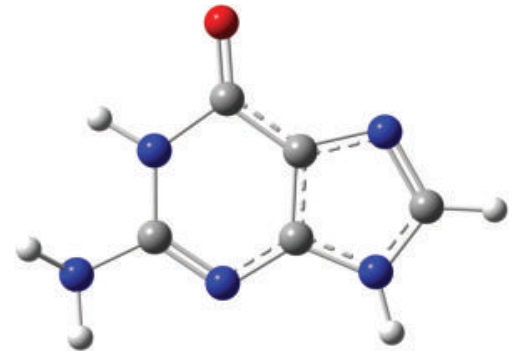

9H-keto-amino

(b)

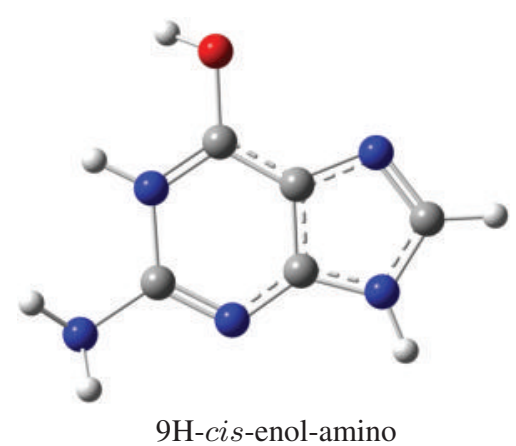

(c)

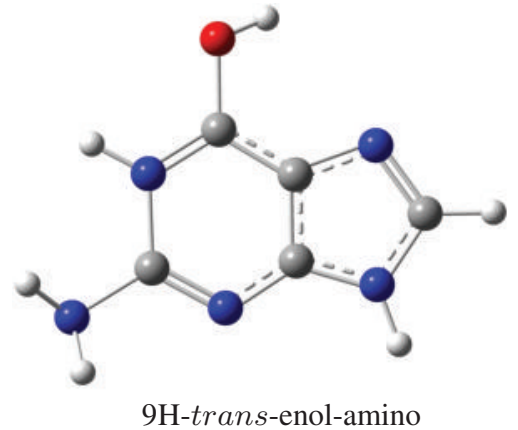

(d)

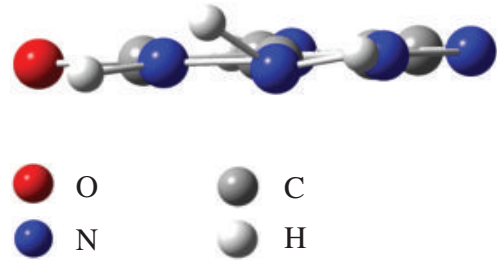

(e)

Figure 1: Structural representation of the calculated (DFT/B3LYP 6-31G ${ }^{* *}$ ) four most stable tautomeric forms of guanine, in the gas phase. (The atom numbering is included. Pyr and Im refer to the pyrimidine and imidazole rings).

the INS spectra. For a mode at a given energy $\nu_{i}$, the intensity from a powdered sample obeys the simplified relationship:

$$
S_{i}^{*}\left(Q, \nu_{i}\right)=\frac{\left(Q^{2} u_{i}^{2}\right) \sigma}{3} \exp \left(-\frac{Q^{2} \alpha_{i}^{2}}{3}\right)
$$

where $Q\left(\AA^{-1}\right)$ is the momentum transferred from the neutron to the sample and $\alpha_{i}(\AA)$ is related to a weighted sum of all the displacements of the atom.

This technique is not limited by selection rules, and it yields not only the energies of the vibrational transitions (the eigenvalues, $\nu_{i}$ ) but also the atomic displacements (the eigenvectors, $u_{i}$ ). This significantly enhances the information obtainable from the vibrational spectrum and adds to that from the complementary Raman and infrared vibrational spectroscopic methods, allowing to detect some low-frequency modes unavailable to these optical techniques. Since the spectral intensities can be quantitatively compared with those calculated by theoretical methods, by combining the INS results with quantum mechanical molecular orbital calculations it is possible to link molecular geometry with the experimental spectroscopic features and produce a consistent conformation for the systems under investigation. 
Despite the usefulness of INS spectroscopy to study low-wavenumber modes (below $1000 \mathrm{~cm}^{-1}$, normally due to the out-of-plane molecular vibrations), the INS intensities decrease considerably above $1000 \mathrm{~cm}^{-1}$ (owing to reduced statistics arising from a considerable decrease of scattered neutron flux, as well as to the instrument effect in this spectral region). This explains the need to use Raman and FTIR techniques (that enable the in-plane modes of vibration to be accessed). Application of all three vibrational techniques to a system allows a complete vibrational assignment in the whole spectral range of interest.

The present study reports a conformational study of anhydrous guanine (7H-keto-amino tautomer, Figure 1(a)) using vibrational spectroscopy techniques coupled to quantum mechanical methods at the Density Functional Theory (DFT) level, both for the isolated molecule and for the solid. It should be emphasized that the INS data presently reported was obtained in the TOSCA spectrometer of the ISIS-pulsed neutron and muon source (UK), which represents a substantial improvement relative to the previously reported results that were acquired in the former TFXA configuration of this spectrometer (allowing a significantly lower resolution and sensitivity).

\section{Methodology}

\subsection{Quantum Mechanical Calculations}

The quantum mechanical calculations were performed using the Gaussian 03W program [22] within the Density Functional Theory (DFT) approach, in order to account for the electron correlation effects. The widely employed hybrid method denoted by B3LYP, which includes a mixture of HF and DFT exchange terms and the gradient-corrected correlation functional of Lee et al. [23] as proposed and parameterised by Becke $[24,25]$ was used, along with the double-zeta split valence basis set $6-31 G^{* *}$ [26]. Molecular geometries were fully optimised by the Berny algorithm, using redundant internal coordinates [27]: the bond lengths to within $c a .0 .1 \mathrm{pm}$ and the bond angles to within $c a .0 .1^{\circ}$. The final

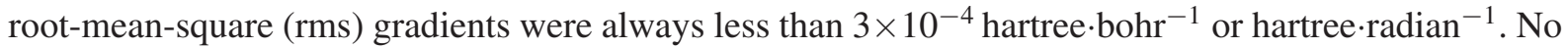
geometrical constraints were imposed on the molecules under study.

The harmonic vibrational wavenumbers, as well as the Raman activities and infrared intensities, were obtained at the same theory level as the geometry optimisation and were scaled according to Merrick et al. [28]. Raman activities, $S_{i}$, in particular, are straightforwardly derived from the program output and cannot be compared directly with the experiment. The theoretical Raman intensity was calculated according to the following equation:

$$
I=C\left(\nu_{0}-\nu_{i}\right)^{4} \frac{S_{i}}{\nu_{i}}
$$

$C$ being a constant and $\nu$ representing frequency values. In order to simulate the linewidth of the experimental lines, an artificial Lorentzian broadening was introduced using the SWizard program (revision 4.6) $[29,30]$. The Raman band half-widths were taken as 10,20 , and $30 \mathrm{~cm}^{-1}$, respectively below $1250 \mathrm{~cm}^{-1}$, between 1250 and $2000 \mathrm{~cm}^{-1}$, and above $2000 \mathrm{~cm}^{-1}$.

The theoretical INS transition intensities were obtained from the calculated normal mode eigenvectors and the spectra simulated using the dedicated aCLIMAX program [31]. 
Plane-wave calculations were performed, based on Density Functional Theory methods within the Perdew-Zunger local density approximation (LDA) [32], and plane wave expansions, as implemented in the PWSCF code from the Quantum Espresso package [33], were used. The atomic coordinates were fully optimised using the published crystal structure of anhydrous guanine as a starting point [9]. Anhydrous guanine crystallizes in a primitive monoclinic space group ( $\left.\mathrm{P} 2_{1} / \mathrm{c}\right)$ with 4 molecules in the unit cell $(z=4)$. The unit cell dimension vectors were conserved during the optimisation process. The pseudopotentials employed were of the norm-conserving type-a Von Barth-Car approach [34] which was applied to the $\mathrm{H}$ and $\mathrm{C}$ atoms, and a Martins-Troullier [35] type was used for the $\mathrm{O}$ and $\mathrm{N}$ atoms. This choice of methods has been guided by the fact that Raman activities can only be calculated with PWSCF methods, using an LDA DFT approach and norm-conserving pseudopotentials. A cut-off energy of 70 Ry and a Monkhorst-Pack grid [36] of $3 \times 3 \times 3$ were found sufficient to attain convergence. The dynamical matrix was calculated for the optimised geometries within the Density Functional Perturbation theory [37] and was diagonalised to obtain the vibrational normal mode wavenumbers, as well as the Raman activities, $S_{i}$.

The Fourier transform infrared (FTIR) spectra were recorded in a Bruker Optics Vertex 70 FTIR spectrometer, in the range $400-4000 \mathrm{~cm}^{-1}$, using $\mathrm{KBr}$ disks $(c a .2 \%(w / w))$, a $\mathrm{KBr}$ beamsplitter, and a liquid nitrogen cooled Mercury Cadmium Telluride (MCT) detector. The FTIR spectra were collected for 2 minutes ( $c a .140$ scans), with a $2 \mathrm{~cm}^{-1}$ resolution. The error in wavenumbers was estimated to be less than $1 \mathrm{~cm}^{-1}$.

The FT-Raman spectrum was gathered at room temperature, in an RFS 100/S Brucker spectrometer. The $1064 \mathrm{~nm}$ line provided by an Nd:YAG laser was used as the incident radiation, providing $c a .300 \mathrm{~mW}$ at the sample position. This excitation energy avoided interference from fluorescence emission by the sample. Resolution was set at $2 \mathrm{~cm}^{-1}$, and a $180^{\circ}$ geometry was employed. The sample was sealed in Kimax glass capillary tubes of $0.8 \mathrm{~mm}$ inner diameter.

INS spectra were obtained in the Rutherford Appleton Laboratory (UK), at the ISIS-pulsed neutron source, in the TOSCA spectrometer. This is an indirect geometry time-of-flight, high resolution $((\triangle E / E) c a .1 .25 \%)$, broad range spectrometer [www.isis.rl.ac.uk]. The samples, Sigma-Aldrich (anhydrous, 99.9+\%), weighing 2-3 grams, were wrapped in aluminium foil to make a $4 \times 4 \mathrm{~cm}$ sachet and placed in thin-walled aluminium cans, which filled the beam. To reduce the impact of the DebyeWaller factor (the exponential term in (1.1)) on the observed spectral intensity, the samples were cooled to $c a .20 \mathrm{~K}$. Data were recorded in the energy range from 16 to $4000 \mathrm{~cm}^{-1}$ and converted to the conventional scattering law, $S(\mathrm{Q}, \nu)$ versus energy transfer $\left(\mathrm{in}^{-1}\right)$ through standard programs.

\section{Results and Discussion}

The lowest energy conformation calculated for isolated guanine, at the DFT B3LYP/6-31G** level, is the $7 \mathrm{H}$-keto-amino tautomer represented in Figure 1(a), with an energy difference of $3.27 \mathrm{KJ} \cdot \mathrm{mol}^{-1}$ relative to the $9 \mathrm{H}$-keto-amino species (Figure 1(b)). The crystal structure of anhydrous guanine was determined by Guille and Clegg [9] and evidences the presence of an essentially planar molecule in the asymmetric unit (Figure 2). The guanine molecules interact within the network via one $\mathrm{O}-\mathrm{HN}$ and two N-HN hydrogen close contacts (the N3, N9, and O6 atoms acting as acceptors). Furthermore, these guanine chains are linked together into sheets through hydrogen bonds involving the N7 and O6 atoms as donor and acceptor, respectively. The three potential H-bond donors, located either in the Pyr or the Im rings, confer a particular structural behaviour to this molecule, as all other nucleic acid bases have 


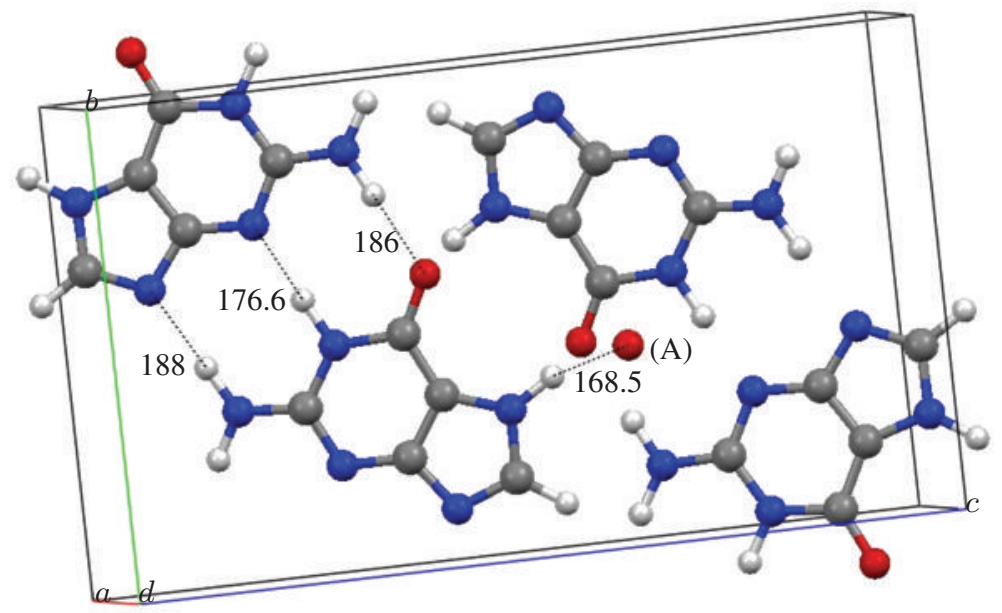

(a)

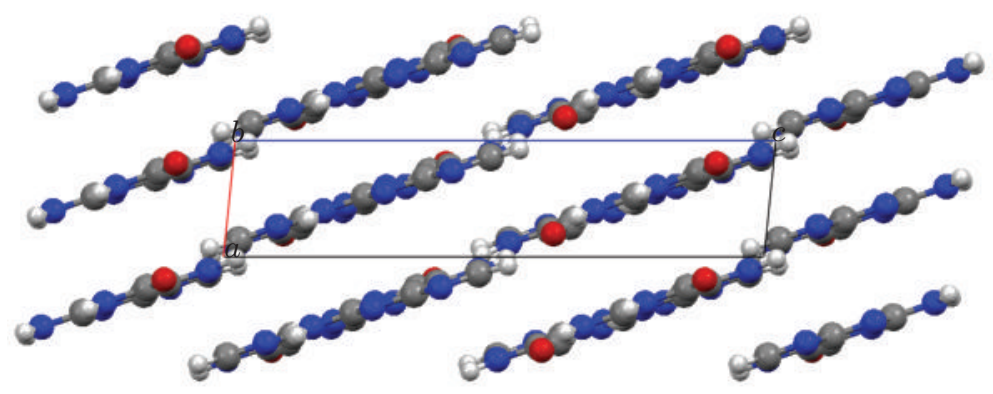

(b)

Figure 2: (a) Optimised crystal cell structure of solid guanine calculated using LDA functional and PW methodology. The dashed lines along with the numbers represent the intermolecular $\mathrm{H}$-bonding distance (measured in picometers). The distance between the two pairs of dimers is about $310.2 \mathrm{pm}$. (A) Oxygen atom from the upper guanine molecule. The remaining atoms were omitted. (b) Lateral view, along the b-axis, of the optimised unit cell.

only two H-bond donor sites. This crystal structure unequivocally shows that, in the absence of a solvent or any other molecules, guanine occurs in the solid-state predominantly as the 7H-keto-amino tautomer (Figure 1(a)), with both N1 and N7 protonated (unlike the monohydrated form).

Table 1 comprises the calculated geometrical parameters for anhydrous guanine, either as an isolated molecule or in condensed phase, as well as the X-ray experimental geometry determined by Guille and Clegg [9]. The optimised structure of isolated guanine is almost planar, except for the amino group (partial $s p^{3}$ hybridization, Figure 1(e)) that imposes $\mathrm{C} 1$ symmetry to the molecule. The dihedral angles defining the position of atoms $\mathrm{H} 10$ and $\mathrm{H} 11$ relative to the plane of the rings are larger than the former ( $c a .39^{\circ}$ out-of-Pyr plane for $\mathrm{H} 10$ versus $c a .11^{\circ}$ for H11, Table 1), with this difference having been previously explained by the strong $\mathrm{H} 10-\mathrm{H}(\mathrm{N} 1)$ repulsion [38-41]. Such $\mathrm{NH}_{2}$ non-planarity is consistent with reported calculations [1, 39, 42, 43] and can be used as a qualitative measure of the accuracy of the basis set. In fact, the addition of polarization functions was shown to be 


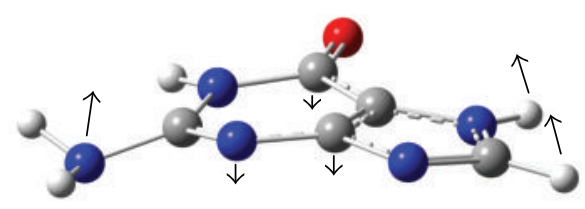

Figure 3: Schematic representation of the low-frequency butterfly mode for guanine.

essential for correctly predicting the nonplanarity of guanine $[38,44]$, although it was found to lead to an overestimation of this geometrical feature.

Interestingly, the same dihedrals measured for the asymmetric unit of anhydrous guanine show a less pronounced shift from planarity for the H10 and H11 atoms: they are found to be out of the pyrimidine plane (out-of-Pyr) by no more than $11^{\circ}$ [9]. PW calculations for the condensed phase, in turn, are in better agreement with these measured dihedrals than the isolated molecule DFT calculations: the $\mathrm{H} 10$ and $\mathrm{H} 11$ are predicted as out-of-Pyr plane by no more than $3^{\circ}$ (Table 1 ). The more planar nature of $\mathrm{NH}_{2}$ group calculated within the $\mathrm{PW}$ methodology may be explained by the presence of intermolecular H-bonding interactions, which are both strong and directional, leading to the repositioning of the amino group in the plane of the molecule. In an attempt to further clarify this question, PW calculations were also performed for the isolated molecule. Several dihedrals involving the H10 and H11 atoms calculated for the isolated molecule were found to be similar to those obtained for the condensed phase (Table 1). Thus, intermolecular H-bonding interactions might not have a preponderant effect in determining the $\mathrm{NH}_{2}$ lack of planarity.

Comparing the calculated bond lengths involving hydrogen atoms, both for the isolated molecule or the solid, with the X-ray data obtained for guanine's asymmetric unit [9], clearly evidences a significant overestimation of these values (Table 1), which is expected since X-ray diffraction locates electron density and not nuclear positions. PW calculations, in turn, yield slightly greater $\mathrm{N}-\mathrm{H}$ bond lengths as compared to the DFT calculated values within the isolated molecule approach (Table 1). Such difference is mainly due to the influence of hydrogen bonding interactions in the condensed phase, which leads to a weakening of the $\mathrm{N}-\mathrm{H}$ bonds and hence to their increased length. Finally, it is worth noticing that all the calculated H-bonding distances in the solid are greatly underestimated as compared to the corresponding experimental values for the unit cell of anhydrous guanine (Table 1). This is a characteristic effect of LDA functionals and is well documented in the literature [45, 46].

The experimental vibrational data presently obtained for guanine-FTIR, Raman, and INS — is comprised in Figures 4 to 6 . Table 2 contains both experimental and calculated wavenumbers, along with the corresponding assignments. Periodic DFT calculations introduce the crystal lattice forces, producing a widely spread spectrum with features that accurately align with the experimental ones. These are mostly characterized by the vibrational modes of the system as a whole, which cannot be generated by an isolated molecule calculation. Indeed, there is a very good agreement between the PW-calculated and the experimental INS spectra (Figure 6), evidencing that the calculated geometry at this theoretical level accurately reproduces the guanine crystalline pattern. In the case of the isolated molecule calculation, the accordance with the experimental INS spectrum is much poorer. In fact, the guanine vibrational modes (namely, the $\mathrm{N}-\mathrm{H}$ wagging) are strongly affected by the H-bonding network in the solid lattice, 
Table 1: Calculated (isolated molecule and condensed phase) and measured (asymmetric unit) geometric parameters for guanine.

\begin{tabular}{|c|c|c|c|c|c|c|c|}
\hline Dihedrals & $\begin{array}{l}\text { Isolated } \\
\text { molecule }{ }^{[\mathrm{a}]}\end{array}$ & $\begin{array}{l}\text { Condensed } \\
\text { phase }^{[b]}\end{array}$ & $\begin{array}{l}\text { Asym- } \\
\text { metric } \\
\text { unit }^{[c]}\end{array}$ & Angles & $\begin{array}{l}\text { Isolated } \\
\text { molecule }\end{array}$ & $\begin{array}{l}\text { Condensed } \\
\text { phase }\end{array}$ & $\begin{array}{l}\text { Asym- } \\
\text { metric } \\
\text { unit }\end{array}$ \\
\hline $\mathrm{H} 10-\mathrm{N} 2-\mathrm{C} 2-\mathrm{N} 3$ & 143.4 & 178.0 & 174.3 & H10-N2-C2 & 116.7 & 123.3 & 118.8 \\
\hline $\mathrm{H} 10-\mathrm{N} 2-\mathrm{C} 2-\mathrm{N} 1$ & -39.1 & -1.8 & -6.7 & H11-N2-H10 & 113.3 & 120.3 & 120.2 \\
\hline H11-N2-C2-N3 & 10.9 & 3.0 & 10.0 & H11-N2-C2 & 111.6 & 116.2 & 119.2 \\
\hline $\mathrm{H} 11-\mathrm{N} 2-\mathrm{C} 2-\mathrm{N} 1$ & -171.6 & -176.8 & -170.9 & $\mathrm{~N} 2-\mathrm{C} 2-\mathrm{N} 1$ & 115.7 & 118.4 & 117.0 \\
\hline N2-C2-N1-H & -2.7 & 3.1 & 2.1 & $\mathrm{~N} 2-\mathrm{C} 2-\mathrm{N} 3$ & 119.9 & 119.5 & 119.6 \\
\hline N2-C2-N1-C6 & -177.2 & -179.7 & 179.5 & $\mathrm{~N} 1-\mathrm{C} 2-\mathrm{N} 3$ & 124.3 & 122.1 & 123.4 \\
\hline $\mathrm{N} 2-\mathrm{C} 2-\mathrm{N} 3-\mathrm{C} 4$ & 176.4 & -179.5 & 179.7 & $\mathrm{C} 2-\mathrm{N} 1-\mathrm{H}$ & 120.1 & 119.3 & 125.2 \\
\hline C2-N3-C4-N9 & -179.3 & 178.9 & 177.7 & C6-N1-H & 114.3 & 115.6 & 110.3 \\
\hline $\mathrm{C} 2-\mathrm{N} 3-\mathrm{C} 4-\mathrm{C} 5$ & 1.6 & -0.8 & -0.6 & C2-N1-C6 & 125.5 & 125.1 & 124.6 \\
\hline $\mathrm{C} 2-\mathrm{N} 1-\mathrm{C} 6-\mathrm{C} 5$ & 0.1 & -0.9 & -0.1 & $\mathrm{~N} 1-\mathrm{C} 6=\mathrm{O}$ & 121.4 & 120.2 & 120.0 \\
\hline N3-C4-C5-C6 & -1.5 & 0.4 & 0.1 & $\mathrm{C} 2-\mathrm{N} 3-\mathrm{C} 4$ & 114.3 & 115.5 & 114.0 \\
\hline N3-C4-N9-C8 & -179.4 & -179.4 & -179.1 & N3-C4-C5 & 124.2 & 124.8 & 125.3 \\
\hline N3-C4-C5-N7 & 179.4 & 179.5 & 179.0 & C5-C6-N1 & 108.7 & 112.4 & 111.8 \\
\hline N3-C2-N1-C6 & 0.1 & 0.6 & -0.4 & N3-C4-N9 & 125.4 & 125.6 & 124.6 \\
\hline N3-C2-N1-H & 174.7 & -176.6 & -178.8 & C5-C4-N9 & 110.4 & 109.6 & 110.2 \\
\hline C4-N9-C8-H & -180.0 & 178.8 & 176.5 & $\mathrm{C} 4-\mathrm{C} 5-\mathrm{N} 7$ & 105.6 & 106.0 & 106.6 \\
\hline C4-N9-C8-N7 & 0.1 & -0.3 & 0.4 & C6-C5-N7 & 131.4 & 133.8 & 132.4 \\
\hline C4-C5-C6-N1 & 0.6 & 0.5 & 0.2 & C4-C5-C6 & 123.0 & 120.2 & 121.0 \\
\hline $\mathrm{C} 4-\mathrm{C} 5-\mathrm{C} 6=\mathrm{O}$ & -178.9 & -179.8 & 179.9 & $\mathrm{C} 5-\mathrm{C} 6=\mathrm{O}$ & 129.8 & 127.4 & 128.3 \\
\hline C4-N3-C2-N1 & 176.4 & 0.3 & 0.7 & C5-N7-H & 125.9 & 129.8 & 131.6 \\
\hline C4-C5-N7-C8 & -0.1 & 0.0 & -0.3 & C8-N7-H & 128.0 & 124.0 & 123.2 \\
\hline $\mathrm{C} 5-\mathrm{N} 7-\mathrm{C} 8-\mathrm{H}$ & -180.0 & -179.0 & -176.0 & C5-N7-C8 & 106.0 & 106.1 & 105.2 \\
\hline C5-N7-C8-N9 & 0.0 & 0.2 & -0.1 & N7-C8-N9 & 113.5 & 113.5 & 114.1 \\
\hline C5-C4-N9-C8 & -0.1 & 0.2 & -0.5 & C8-N9-C4 & 104.5 & 104.9 & 103.9 \\
\hline C5-C6-N1-H & -174.8 & 176.4 & 178.5 & N7-C8-H & 121.7 & 121.6 & 125.0 \\
\hline C6-C5-N7-H & 0.8 & -3.9 & -2.1 & N9-C8-H & 124.9 & 124.9 & 120.8 \\
\hline
\end{tabular}


Table 1: Continued.

\begin{tabular}{|c|c|c|c|c|c|c|}
\hline Dihedrals & $\begin{array}{l}\text { Isolated } \\
\text { molecule }^{[\mathrm{a}]}\end{array}$ & $\begin{array}{l}\text { Condensed } \\
\text { phase }^{[\mathrm{b}]}\end{array}$ & $\begin{array}{l}\text { Asymmetric } \\
\text { unit }^{[c]}\end{array}$ & Angles & $\begin{array}{l}\text { Isolated Condensed } \\
\text { molecule phase }\end{array}$ & $\begin{array}{l}\text { Asym- } \\
\text { metric } \\
\text { unit }\end{array}$ \\
\hline C6-C5-N7-C8 & -179.1 & 179.0 & 178.5 & & & \\
\hline C6-C5-C4-N9 & 179.2 & -179.3 & -178.4 & & & \\
\hline N1-C6-C5-N7 & 179.4 & -178.4 & 178.3 & & & \\
\hline N9-C4-C5-N7 & 0.1 & -0.2 & 0.5 & & & \\
\hline N9-C8-N7-H & -179.8 & -177.2 & -179.6 & & & \\
\hline $\mathrm{N} 7-\mathrm{C} 5-\mathrm{C} 6=\mathrm{O}$ & 0.0 & 1.3 & 1.3 & & & \\
\hline $\mathrm{H}-\mathrm{C} 8-\mathrm{N} 7-\mathrm{H}$ & 0.2 & 3.7 & 4.5 & & & \\
\hline $\mathrm{H}-\mathrm{N} 1-\mathrm{C} 6=\mathrm{O}$ & 4.7 & -3.3 & -1.2 & & & \\
\hline
\end{tabular}

\begin{tabular}{lcccccccc}
\hline $\begin{array}{l}\text { Bond } \\
\text { lengths }\end{array}$ & \multicolumn{2}{c}{ Isolated } & Condensed & Asymmetric & H-Bonding & \multicolumn{5}{c}{ Condensed phase } \\
\hline H10-N2 & 101.1 & 104.8 & 84.0 & N2-H10-N9 & 104.8 & 188.0 & 292.8 & 179.3 \\
H11-N2 & 101.2 & 104.1 & 88.1 & N2-H11-O & 104.1 & 186.0 & 290.1 & 179.0 \\
N2-C2 & 138.2 & 132.7 & 133.0 & N1-H-N3 & 107.9 & 176.6 & 284.3 & 176.7 \\
C2-N1 & 138.2 & 137.2 & 137.1 & N7-H-O & 106.1 & 168.5 & 272.0 & 163.6 \\
C2-N3 & 130.5 & 132.7 & 133.0 & & & & & \\
\hline N1-H & 101.3 & 107.9 & 90.9 & & & Asymmetric unit & \\
N3-C4 & 136.8 & 133.8 & 135.6 & N2-H10-N9 & 84.0 & 217.1 & 300.6 & 172.0 \\
N1-C6 & 142.0 & 137.8 & 138.7 & N2-H11-O & 88.1 & 202.4 & 290.2 & 174.3 \\
C4-C5 & 139.5 & 139.6 & 137.8 & N1-H-N3 & 90.9 & 196.8 & 286.1 & 166.7 \\
C6-C5 & 142.8 & 140.4 & 141.2 & N7-H-O & 99.6 & 176.7 & 274.2 & 165.4 \\
C6=O & 122.6 & 125.7 & 124.9 & & & & & \\
C4-N9 & 137.4 & 135.8 & 136.4 & & & & & \\
C5-N7 & 137.8 & 137.0 & 137.2 & & & & & \\
N7-H & 100.9 & 106.1 & 99.6 & & & & & \\
N7-C8 & 136.4 & 133.9 & 134.3 & & & & & \\
C8-H & 108.2 & 109.4 & 97.1 & & & & & \\
N9-C8 & 132.0 & 132.6 & 132.8 & & & & & \\
\hline
\end{tabular}

[a]At the DFT B3LYP/6-31G** level of theory. [b]With the PWSCF/LDA methodology. [c]Geometric parameters obtained from X-ray diffraction data (CIF file provided. [9]).

as expected, leading to a marked disagreement between the isolated molecule calculations and the experimental data below $1000 \mathrm{~cm}^{-1}$.

Isolated guanine has 42 vibrational modes, 27 in-plane and 15 out-of-plane. Regarding the condensed phase calculations, only the internal coordinates of all 64 atoms that comprise the unit cell were optimised. No full optimisation, concerning the molecule's dimensions and volume, was 


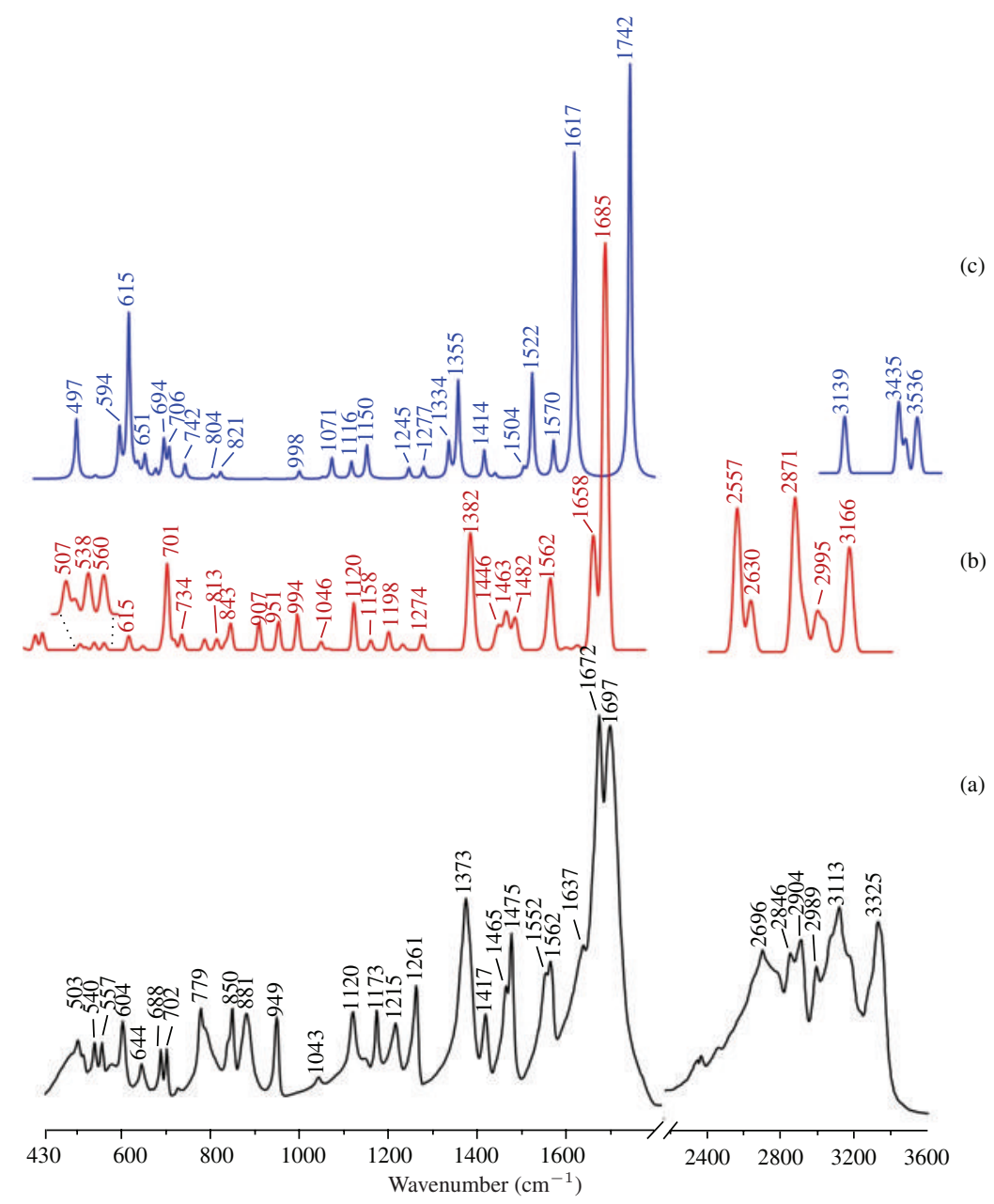

Figure 4: FTIR spectra of anhydrous guanine. Experimental (a). Calculated, for the condensed state (b) and for the isolated molecule (c). (The band at $1672 \mathrm{~cm}^{-1}$ in spectrum (a) was taken as a reference for vertical scaling).

performed, mainly due to the high computational cost involved. The lack of a full-optimised unit cell might contribute for small discrepancies between calculated and experimental vibrational spectra, since the guanine crystal structure was obtained at $120 \mathrm{~K}$ and spectroscopic experiments were recorded at $20 \mathrm{~K}$ (INS) and at room temperature ( $c a .293 \mathrm{~K}$ ) (Raman and FTIR). As the PW calculation are carried out at $0 \mathrm{~K}$, a contraction of the cell volume relative to the experimental data is to be expected. Therefore, geometry optimisations in van der Waals solids is generally limited to the atomic coordinates to avoid expansion of the cell. On the other hand, most DFT calculations using full optimisation normally underestimate long-range dispersive interactions, due to mutually induced dipoles. Furthermore, the work reported by Plazanet and collaborators on polycrystalline-hydrated guanine [47] showed no appreciable differences upon calculation of the periodic DFT INS eigenvalues and eigenvectors after atomic coordinates optimisation, or after atomic coordinate plus unit cell geometry optimisation. 


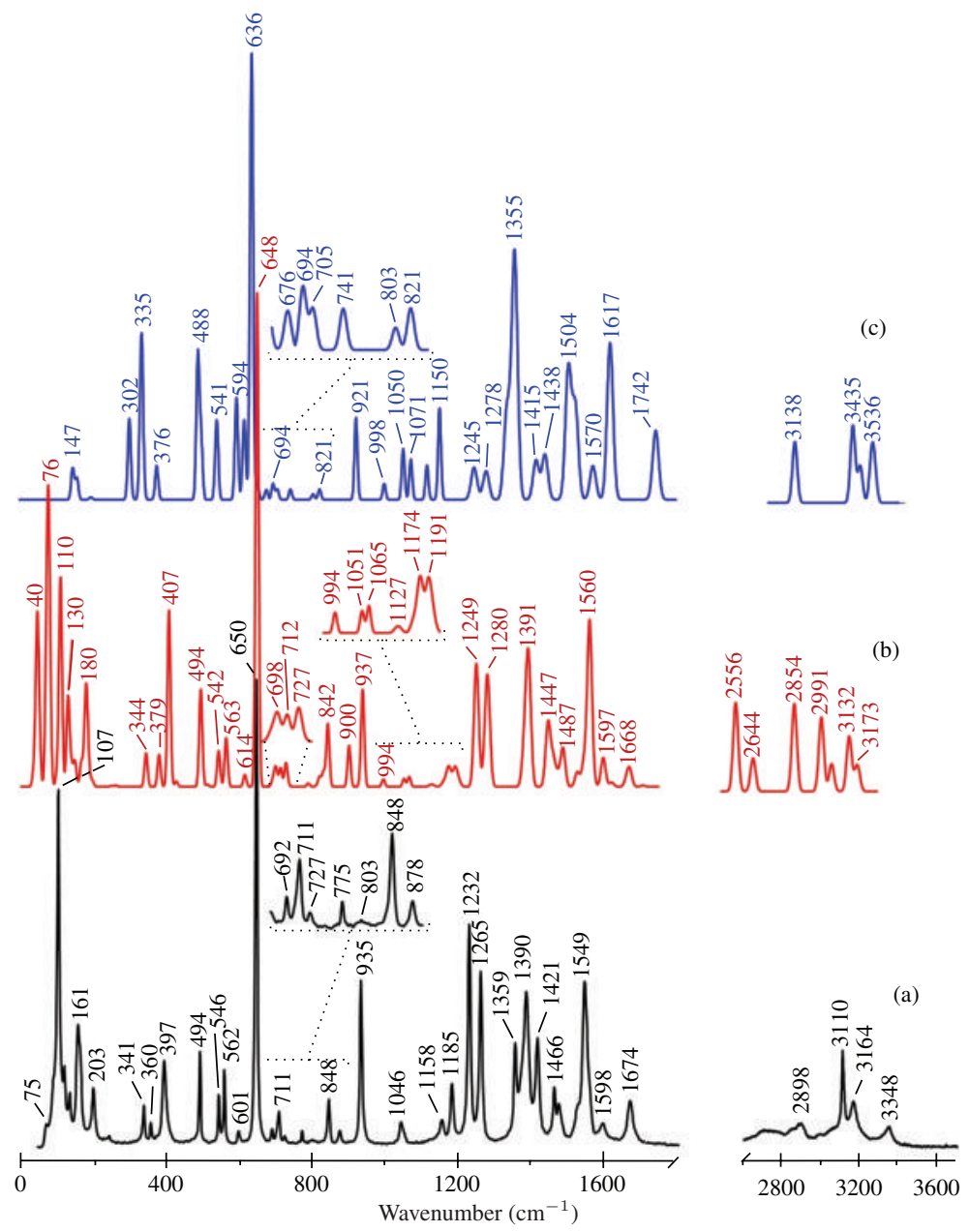

Figure 5: Raman spectra of anhydrous guanine. Experimental (a). calculated, for the condensed state (b) and for the isolated molecule (c). (The band at $650 \mathrm{~cm}^{-1}$ in spectrum (a) was taken as reference for vertical scaling).

Condensed-phase calculations revealed that the four guanine molecules in the unit cell originate 192 harmonic vibrational frequencies, that can be numerically arranged in sets of four. Table 2 comprises only 188 of these wavenumbers, since two of them were imaginary values and thus the first set comprising external mode vibrations was disregarded.

There is almost no information to be found in the literature concerning the low-frequency vibrational modes of guanine. In fact, the INS results described by Ghomi and collaborators [12, 17] and by Gaigeot et al. [16] display a quite poor resolution in this spectral region as compared to the INS data presently reported, partly because they were obtained using the initial configuration (TFXA) of the present TOSCA spectrometer of the ISIS Facility. The most intense features presently obtained below $500 \mathrm{~cm}^{-1}$ (Figure 6(a)) were assigned, in the light of the PW-calculated modes, to a coupling between H-bonding, lattice longitudinal and transversal vibrations and skeletal ring vibrations: the strong band 


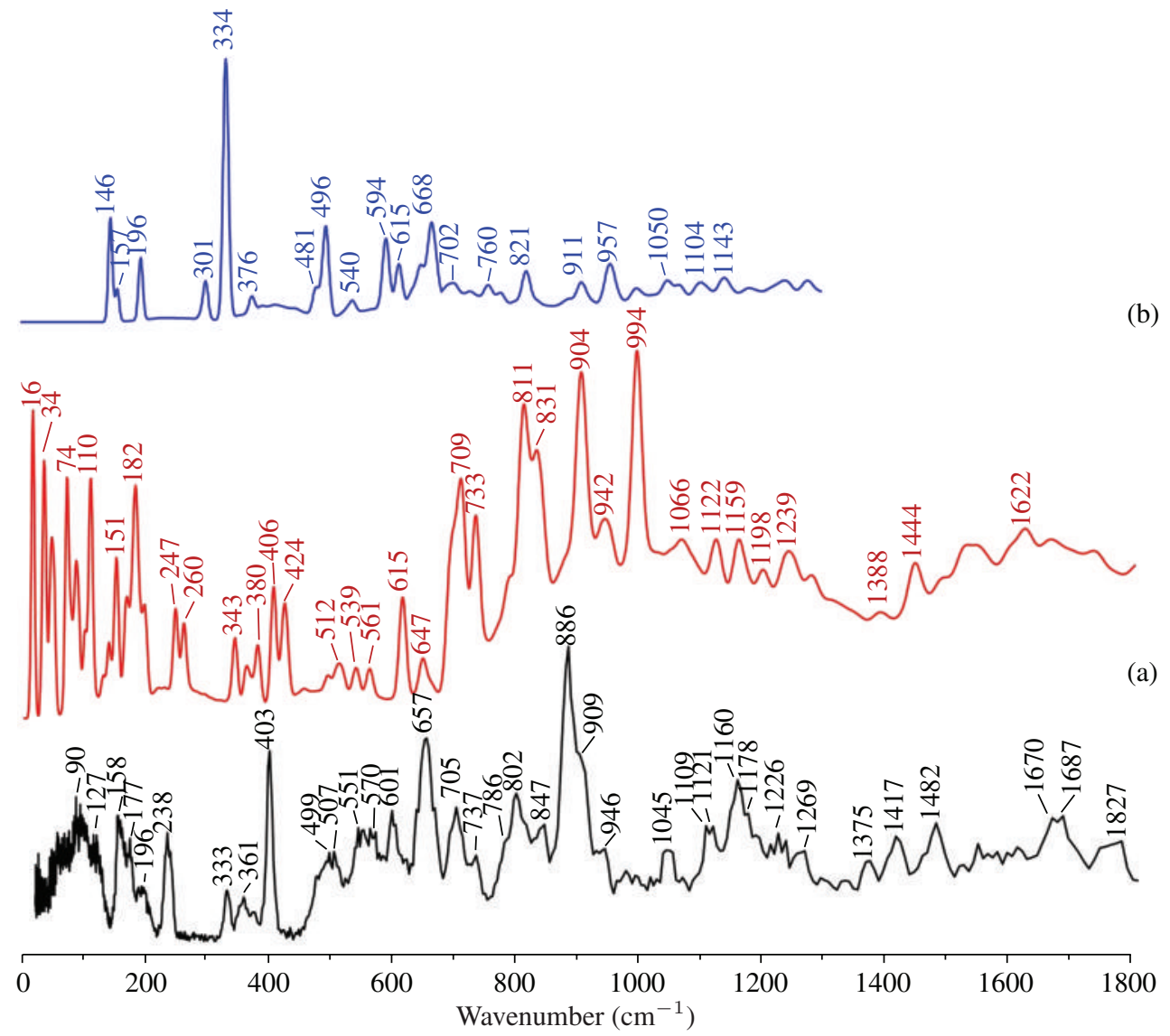

Figure 6: Solid-state INS spectra of anhydrous guanine. Experimental (a); calculated, for the condensed state (b) and for the isolated molecule (c).

at $158 \mathrm{~cm}^{-1}$ is mainly due to the skeletal ring torsions (butterfly mode, Figure 3), while the one at $238 \mathrm{~cm}^{-1}$ arises specifically from the C2-N1-C6 out-of-plane deformation of Pyr atoms (very weak in Raman, at $245 \mathrm{~cm}^{-1}$, Figure 5(a)). The deformation of amine and carbonyl groups was found to be synchronized, which originates a change in the hydrogen-bond lengths connecting the two guanine molecules in the same sheet- N2-H10-N9 and N2-H11-O lengths (Figure 2). This effect is outlined in Table 2 as "H-bond effect" and might account for the very strong intensity of the $403 \mathrm{~cm}^{-1}$ INS band. The PW calculated INS spectrum fails to accurately reproduce the intensity of this band, yielding two, less intense, peaks at 406 and $424 \mathrm{~cm}^{-1}$ instead (Figure 6(b)). This is probably due to a limitation of the LDA functional for properly considering the "H-bond effect" contribution to the vibrational mode. The corresponding Raman feature at $397 \mathrm{~cm}^{-1}$ (Figure 5(a)) is also quite intense, which supports its assignment to the in-plane amino and carbonyl group deformations (Table 2). In fact, the present assignment excludes out-of-plane contributions (which are more intense in INS than the in-plane ones), despite the very strong intensity of the $403 \mathrm{~cm}^{-1}$ INS band and its proximity to the out-of-plane 
deformation region of Pyr and Im rings involving the N7, N9, and N3 atoms (361 and $379 \mathrm{~cm}^{-1}$ INS bands and $360 \mathrm{~cm}^{-1}$ Raman signal-Table 2 and Figures 6(a) and 5(a), respectively). A contribution from such out-of-plane motions to the $403 \mathrm{~cm}^{-1}$ INS feature $\left(397 \mathrm{~cm}^{-1}\right.$ in Raman) might occur, although it was not predicted by the presently condensed phase or isolated molecule calculations.

The INS spectrum of guanine displays two neighbouring bands at 499 and $507 \mathrm{~cm}^{-1}$ (Figure 6) both ascribed to the in-plane deformation of Pyr ring atoms (Table 2). These features are proposed to result from a factor group splitting (Davydov splitting), which leads to the separation of vibrational bands ascribed to the same mode due to the presence of more than one interacting equivalent molecular entity in the unit cell. Other Davydov phenomena seem to appear in guanine's INS profile, namely, at $1109 / 1121 \mathrm{~cm}^{-1}$ and $1670 / 1687 \mathrm{~cm}^{-1}$ (Figure 6). This splitting is only detected in the INS spectrum, single bands at $494 \mathrm{~cm}^{-1}$ in Raman and at $503 \mathrm{~cm}^{-1}$ in FTIR spectra being observed (Figures 4(a) and 5(a)). Previous INS data reported by Ghomi [12, 17] and by Plazanet et al. [47] failed to distinguish this effect for lack of spectral resolution.

The signal around $600 \mathrm{~cm}^{-1}$, clearly observed in INS (at $601 \mathrm{~cm}^{-1}$ ) and in FTIR (at $604 \mathrm{~cm}^{-1}$ ) but very weak in Raman (at $600 \mathrm{~cm}^{-1}$, Table 2), is ascribed to an out-of-plane vibration. PW normal coordinate analysis led to the assignment of this band to the Im ring deformation, with a special contribution from the out-of-plane, (C8-N7-C5) and (C4-N9-C8), deformation modes. These motions also imply the displacement of $(\mathrm{N} 7) \mathrm{H}$ and $(\mathrm{C} 8) \mathrm{H}$ hydrogen atoms, which account for the strong $601 \mathrm{~cm}^{-1}$ INS feature. Such assignment is not in agreement with the majority of guanine vibrational reports to be found in the literature to this date, according to which this feature would be mainly due to the $\mathrm{NH}_{2}$ and $(\mathrm{N} 1) \mathrm{H}$ wagging motions $[18,19,38]$. However, none of these studies considers anhydrous guanine, being based on the polycrystalline hydrated form instead and using calculation levels of theory quite lower than the presently applied PWSCF methodology.

The most intense feature in the Raman spectrum, observed at $650 \mathrm{~cm}^{-1}\left(657 \mathrm{~cm}^{-1}\right.$ in INS) (Figure 5), is ascribed to the in-plane/in-phase stretching of the purine ring (breathing mode). This guanine breathing motion is well documented $[11,13,44]$ and is worth noticing since it is often used as a spectroscopic probe for DNA conformational studies, allowing to distinguish between $\mathrm{B}$ and $\mathrm{Z}$ conformations (based on the ration between $\mathrm{C} 3$-endo and $\mathrm{C} 2$-endo arrangements). This signal was also proposed as a conformation marker in GMP, given that it is affected by coupling with the N9-C'1 vibrational mode $[44,48]$.

The INS signals centred at 705 and $737 \mathrm{~cm}^{-1}$ arise from a mixture of Pyr in-plane and out-ofplane deformations, mainly characterised by the inversion of the $\mathrm{C} 4, \mathrm{C} 5$, and $\mathrm{C} 6$ carbon atoms above and below the Pyr plane (symmetric deformation or umbrella mode). The signals at 802 and $847 \mathrm{~cm}^{-1}$ display a similar profile (Figure 6(a)), with a higher intensity due to the additional contribution of several motions involving the displacement of $\mathrm{H}$ atoms (e.g., $\mathrm{NH}_{2}$ torsion, twisting and wagging modes). These four bands span over a spectral region between 700 and $850 \mathrm{~cm}^{-1}$, with almost unnoticeable Raman features but strong INS bands due to the out-of-plane motions (Table 2). It is worth noticing that the predicted $\mathrm{NH}_{2}$ wagging mode is greatly underestimated for the isolated molecule $\left(615 \mathrm{~cm}^{-1}\right)$ as opposed to the condensed phase $\left(710 \mathrm{~cm}^{-1}\right.$, Table 2 and Figure 6). Such difference results from H-bond interactions in the solid state, that hinder the motion of hydrogen atoms and lead to a blue shift of the out-of-plane $\mathrm{NH}_{2}$ vibrations (wagging, twisting, torsion).

The most intense INS band, at $886 \mathrm{~cm}^{-1}$ (with a shoulder at $909 \mathrm{~cm}^{-1}$, Table 2) is assigned to the $(\mathrm{C} 8) \mathrm{H}$ and $(\mathrm{N} 7) \mathrm{H},(\mathrm{N} 1) \mathrm{H}$ out-of-plane deformations, coupled to the $\mathrm{NH}_{2}$ twisting mode. These 
Table 2: Experimental and calculated wavenumbers for anhydrous guanine.

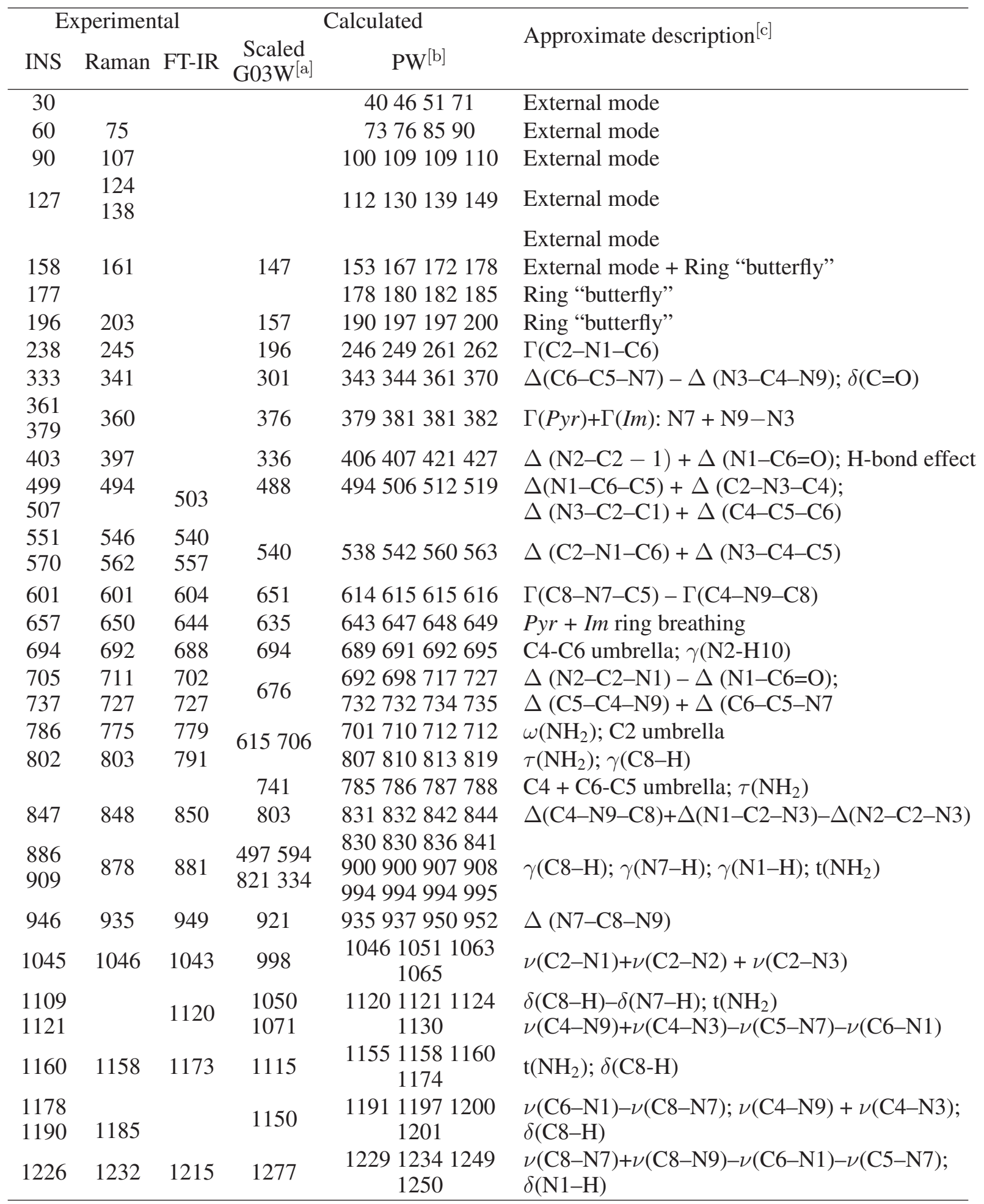


Table 2: Continued.

\begin{tabular}{|c|c|c|c|c|c|}
\hline \multicolumn{3}{|c|}{ Experimental } & \multirow[b]{2}{*}{$\begin{array}{l}\text { Scaled } \\
\text { G03W }\end{array}$} & Calculated & \multirow{2}{*}{ Approximate description ${ }^{[\mathrm{c}]}$} \\
\hline INS & Raman & FT-IR & & $\mathrm{PW}^{[\mathrm{b}]}$ & \\
\hline 1269 & 1265 & 1261 & 1245 & 1274127512801281 & $\begin{array}{l}\nu(\mathrm{N} 9-\mathrm{C} 8)+\nu(\mathrm{C} 5-\mathrm{C} 6)-\nu(\mathrm{C} 4-\mathrm{N} 9)-\nu(\mathrm{C} 6-\mathrm{N} 1) \\
\delta(\mathrm{C} 8-\mathrm{H})\end{array}$ \\
\hline $\begin{array}{l}1375 \\
1406\end{array}$ & $\begin{array}{l}1359 \\
1390\end{array}$ & 1373 & $\begin{array}{l}1334 \\
1355\end{array}$ & $\begin{array}{l}1379138013821384 \\
1386139113941395\end{array}$ & $\begin{array}{l}\nu(\mathrm{C} 4-\mathrm{N} 3)+\nu(\mathrm{C} 5-\mathrm{C} 6)+\nu(\mathrm{C} 4-\mathrm{C} 5)+\nu(\mathrm{C} 2-\mathrm{N} 1)- \\
\nu(\mathrm{C} 4-\mathrm{N} 9)-\nu(\mathrm{C} 5-\mathrm{N} 7)-\nu(\mathrm{C} 8-\mathrm{N} 9)\end{array}$ \\
\hline 1417 & 1421 & 1417 & $\begin{array}{l}1414 \\
1438\end{array}$ & 1441144114471447 & $\delta(\mathrm{N} 1-\mathrm{H}) ; \nu(\mathrm{C} 2-\mathrm{N} 2)+\nu(\mathrm{C} 5-\mathrm{C} 6)-\nu(\mathrm{C} 8-\mathrm{N} 9)$ \\
\hline 1463 & 1466 & 1465 & 1504 & 1460146014631473 & $\begin{array}{l}\nu(\mathrm{C} 8-\mathrm{N} 9)+\nu(\mathrm{C} 2-\mathrm{N} 1)+\nu(\mathrm{C} 6-\mathrm{N} 1)-\nu(\mathrm{C} 8-\mathrm{N} 7)- \\
\nu(\mathrm{C} 2-\mathrm{N} 3) \\
\delta(\mathrm{C} 8-\mathrm{H})\end{array}$ \\
\hline 1482 & 1479 & 1475 & 1522 & 1482148314871491 & $\nu(\mathrm{C} 8-\mathrm{N} 7)-\nu(\mathrm{C} 5-\mathrm{N} 7) ; \delta(\mathrm{N} 7-\mathrm{H})$ \\
\hline 1550 & 1549 & $\begin{array}{l}1552 \\
1562\end{array}$ & 1617 & $\begin{array}{r}1526154115451549 \\
1560156015631567\end{array}$ & $\begin{array}{l}\alpha\left(\mathrm{NH}_{2}\right) ; \nu(\mathrm{C} 8-\mathrm{N} 9)+\nu(\mathrm{C} 4-\mathrm{N} 9)+\nu(\mathrm{C}=\mathrm{O})+ \\
\nu(\mathrm{C} 2-\mathrm{N} 2) ; \nu(\mathrm{N} 3-\mathrm{C} 4)-\nu(\mathrm{C} 4-\mathrm{C} 5)-\nu(\mathrm{N} 3-\mathrm{C} 2) \\
\delta(\mathrm{N} 1-\mathrm{H})\end{array}$ \\
\hline 1550 & 1549 & $\begin{array}{l}1552 \\
1562\end{array}$ & 1617 & $\begin{array}{l}1526154115451549 \\
1560156015631567\end{array}$ & $\begin{array}{l}\alpha\left(\mathrm{NH}_{2}\right) ; \nu(\mathrm{C} 8-\mathrm{N} 9)+\nu(\mathrm{C} 4-\mathrm{N} 9)+\nu(\mathrm{C}=\mathrm{O})+ \\
\nu(\mathrm{C} 2-\mathrm{N} 2) ; \nu(\mathrm{N} 3-\mathrm{C} 4)-\nu(\mathrm{C} 4-\mathrm{C} 5)-\nu(\mathrm{N} 3-\mathrm{C} 2) \\
\delta(\mathrm{N} 1-\mathrm{H})\end{array}$ \\
\hline $\begin{array}{l}1670 \\
1687\end{array}$ & 1674 & $\begin{array}{l}1672 \\
1697\end{array}$ & 1742 & $\begin{array}{l}1657166216681670 \\
1671168416851706\end{array}$ & $\begin{array}{l}\alpha\left(\mathrm{NH}_{2}\right) ; \nu(\mathrm{C} 2-\mathrm{N} 1)+\nu(\mathrm{C} 2-\mathrm{N} 3)+ \\
\nu(\mathrm{C} 5-\mathrm{C} 6)-\nu(\mathrm{C}=\mathrm{O})-\nu(\mathrm{C} 2-\mathrm{N} 2) ; \delta(\mathrm{N} 1-\mathrm{H})\end{array}$ \\
\hline & 2708 & 2696 & & & Combination mode \\
\hline & 2898 & $\begin{array}{l}2846 \\
2904\end{array}$ & 3472 & 2556255626302644 & $\nu(\mathrm{N} 1-\mathrm{H})$ \\
\hline & 2992 & 2989 & 3531 & 2854285428712919 & $\nu(\mathrm{N} 7-\mathrm{H})$ \\
\hline & $\begin{array}{l}3110 \\
3164\end{array}$ & $\begin{array}{l}3064 \\
3113 \\
3178\end{array}$ & 3435 & 2991299130353043 & $\nu_{s}\left(\mathrm{NH}_{2}\right)$ \\
\hline & 3348 & 3325 & $\begin{array}{l}3139 \\
3536\end{array}$ & $\begin{array}{l}3132313231333134 \\
3166316731733177\end{array}$ & $\begin{array}{l}\nu(\mathrm{C} 8-\mathrm{H}) \\
\nu_{a}\left(\mathrm{NH}_{2}\right)\end{array}$ \\
\hline
\end{tabular}

[a]At the DFT B3LYP/6-31G** level of theory. The calculated vibrational modes were scaled accordingly to [28]. [b]Using the LDA functional and Plane-Wave methodology, unscaled. [c]According to the PW description. The "+" and "-" signals represent vibrations occurring simultaneously in the same direction or in opposite directions, respectively. $\omega$ : wagging; $\delta$ : in-plane deformation; $\Delta$ : in-plane ring deformation of skeletal atoms; $\gamma$ : out-of-plane deformation; $\Gamma$ : out-of-plane ring deformation of skeletal atoms (umbrella mode); $\alpha$ : scissoring; $\tau$ : torsion; t: twisting; $\nu_{s}$ : symmetric stretching; $\nu_{a}$ : antisymmetric stretching.

yield a Raman signal at $878 \mathrm{~cm}^{-1}$, with a very weak intensity probably due to its out-of-plane character. The difference between PW and isolated molecule calculated normal modes for this specific vibration is remarkable and reflects the convenience of high level Plane-Wave calculations for accurately reproducing the vibrational spectra of crystalline systems with extended $\mathrm{H}$-bond interactions: the $\mathrm{NH}_{2}$ twisting, for instance, calculated for the isolated molecule at $334 \mathrm{~cm}^{-1}$ (Table 2), is underestimated (red-shifted) by more than $400 \mathrm{~cm}^{-1}$ as compared to the PW calculated value (between 785 and 
$819 \mathrm{~cm}^{-1}$ ). The same occurs for the N1-H and N7-H out-of-plane motions, calculated for the gas at 594 and $497 \mathrm{~cm}^{-1}$, respectively, underestimated by more than $300 \mathrm{~cm}^{-1}$ relative to the solid-state values. Nevertheless, some PW calculated eigenvectors for modes involving $\mathrm{H}$ displacements (Figure 6(b)) are not totally satisfactory and fail, to some extent, to predict the experimental shape of the INS profile: the $\gamma(\mathrm{N} 1-\mathrm{H})$ mode, in particular, is calculated at $994 \mathrm{~cm}^{-1}$ with an intensity quite different from the experimental one (Figure 6(a)). Previous assignments reported by Goulombeau et al. agree well with the presently proposed ones for the very strong INS feature at $886 \mathrm{~cm}^{-1}$ [12], but not with those proposed by Giese and McNaughton [38], who assigned the $\gamma(\mathrm{N} 9-\mathrm{H})$ and $\gamma(\mathrm{N} 1-\mathrm{H})$ motions to the $603 \mathrm{~cm}^{-1}$ feature.

The very intense Raman band at $935 \mathrm{~cm}^{-1}$, which corresponds to a weak INS feature at $946 \mathrm{~cm}^{-1}$, is assigned to the in-plane (N7-C8-N9) deformation. Its sharpness in the Raman spectrum reflects the highly symmetrical character of this vibrational mode [49].

The spectral region above $1000 \mathrm{~cm}^{-1}$ contains mostly in-plane modes, all Raman active. The weak $1046 \mathrm{~cm}^{-1}$ band results from contributions involving Pyr/Im N-C stretching modes, specially those involving the $\mathrm{C} 2$ carbon atom. Some reported assignments also suggest a contribution from inplane $(\mathrm{C} 8) \mathrm{H}$ and $(\mathrm{N}) \mathrm{H}$ deformations $[38,50]$ to this feature, which was not, however, observed in the present work. In the light of the PW calculations, the in-plane motions involving $\mathrm{H}$ atoms yield two INS bands at 1109 and $1121 \mathrm{~cm}^{-1}$, and also account for the strong $1160 \mathrm{~cm}^{-1}$ INS signal and the $1173 \mathrm{~cm}^{-1}$ FTIR feature. Both FTIR and Raman spectra display four well-defined bands between 1120 and $1260 \mathrm{~cm}^{-1}$ (Figures 4(a) and 5(a)), that result from couplings between different C-N/C-C stretching and $\mathrm{C}-\mathrm{H} / \mathrm{N}-\mathrm{H}$ bending modes. The two bands at higher frequencies (at 1232 and $1265 \mathrm{~cm}^{-1}$ ), very strong in Raman, have been reported as hydrogen-bond markers due to the very large red-shift ( $c a$. $250 \mathrm{~cm}^{-1}$ ) that they undergo upon N-H and C-H deuteration [38].

Regarding the infrared data, the broad feature at $1373 \mathrm{~cm}^{-1}$ (Figure 4(a)), corresponding to the 1359 and $1390 \mathrm{~cm}^{-1}$ Raman bands (Table 2), was reported as being due to a complex coupling of C-N and $\mathrm{C}-\mathrm{C}$ stretching modes of the Pyr+Im rings, particularly involving the $\mathrm{C} 4$ and $\mathrm{C} 5$ atoms $[4,19,49]$. The description of this mode can be easily depicted considering the stretching of the (C5-N7) and (C4N9) bonds in the same direction, simultaneously with the squeezing of the (C5-C6) and (C4-N3) bonds (i.e., the Im ring stretches while the Pyr ring squeezes, Figure 1).

Also noteworthy is the apparent disagreement in the reported literature regarding the assignment of the two most intense FTIR bands, centred at 1672 and $1697 \mathrm{~cm}^{-1}$, corresponding to the Raman signal at $1674 \mathrm{~cm}^{-1}$. McNaughton et al. $[19,20]$ ascribed this Raman signal to the $\mathrm{C}=\mathrm{O}$ stretching coupled with the (N1)H in-plane bending, while Florián [18] ascribed it to the $\mathrm{NH}_{2}$ scissoring mode. Delabar and coworkers, in turn, [11] assigned these two infrared bands to the $\mathrm{NH}_{2}$ scissoring and $\mathrm{C}=\mathrm{O}$ stretching modes, respectively, and the Raman feature solely to the $\mathrm{C}=\mathrm{O}$ stretching. In the present work, it is suggested that the two FTIR bands are due to $\nu(\mathrm{C}=\mathrm{O})$ coupled with the $\mathrm{NH}_{2}$ scissoring and $(\mathrm{N} 1) \mathrm{H}$ inplane bending vibrations. In the light of the PW calculations, no real separation between the carbonyl stretching and the $\mathrm{NH}_{2}$ scissoring is observed: both FTIR bands have a hybrid coupling between these modes and both match the Raman feature at $1674 \mathrm{~cm}^{-1}$. The proposed assignment is also supported by the remarkable agreement found between the PW calculated and experimental spectral intensities (Figures 5(a) and 5(b)). However, the accurate distinction of the two FTIR bands is quite difficult, as there is no straightforward reason for the presence of two bands instead of one: it is possible that they correspond to a Davydov splitting, also observed in the INS spectrum (at 1670 and $1687 \mathrm{~cm}^{-1}$, Figure 6(a)). 
The high-frequency FTIR spectrum of guanine (between 2000 and $3600 \mathrm{~cm}^{-1}$ ) displays very broad bands. Five signals are expected from the calculations, corresponding to stretching modes from $\mathrm{NH}_{2}$ (symmetric and anti symmetric), $(\mathrm{N} 1) \mathrm{H},(\mathrm{N} 7) \mathrm{H}$, and $(\mathrm{C} 8) \mathrm{H}$, without extensive hybrid couplings. It is interesting to note that the $(\mathrm{N} 1) \mathrm{H}$ and $(\mathrm{N} 7) \mathrm{H}$ stretchings are markedly overestimated by the isolated molecule calculations as compared to the PW methodology. In fact, they are experimentally detected at lower wavenumbers as a consequence of their involvement in intermolecular H-bonding. The proposed approximate description presented in Table 2 is based on the PW results only, since the normal modes calculated for the isolated molecule deviate dramatically from the experimental data. The involvement of the amine group in intermolecular H-bonding can also account for the two well-defined shoulders detected at 3064 and $3178 \mathrm{~cm}^{-1}$. Once more, the importance of a correct representation of the intermolecular H-bonding profile in guanine is evident when analysing the amine stretching modes, greatly affected by this type of close contacts.

\section{Conclusion}

Nucleic acid bases, particularly guanine (and its analogues), play a fundamental role in biochemistry due to their essential biological role and mutagenic potential. These molecules have a very large range of protonation and tautomeric species, which justifies the difficulty in predicting their stability and relative population. Even using advanced spectroscopic methods, the subtle conformational changes that occur upon tautomeric equilibria are difficult to grasp, which renders the spectral assignment a complex task. Accordingly, up-to-date ab initio calculations became of the utmost importance in order to fully understand the structural and spectroscopic properties of this kind of systems. In the present work, a full vibrational spectroscopic study of the $7 \mathrm{H}$-keto-amino tautomeric form of guanine was performed, in the light of DFT calculations (both for the isolated molecule and the condensed phase).

A complete and accurate assignment of the experimental spectra was achieved, due to the combination of all the available spectroscopic vibrational techniques (FTIR, Raman, and INS) with state-of-the-art theoretical approaches. Within the latter, condensed-phase periodic DFT calculations were used, which, to the best of the authors' knowledge, are the highest level of theory applied so far to the study of nucleic acid bases.

A very good agreement was obtained between predicted and experimental spectra, mainly for the Raman and INS data (both regarding frequencies and intensities). Specifically regarding the INS profile, detailed features such as Davydov splittings and vibrational modes associated to intermolecular $\mathrm{H}$-bond interactions could be unequivocally assigned for the first time. The results thus obtained clearly evidence the need for using periodic functionals (e.g., Plane-Wave approach) for the representation of this molecule in the solid state. In particular, the low energy region of the spectrum, comprising external (lattice) modes, can only be accurately predicted through such a PW methodology.

In summary, this study represents the most reliable vibrational assignment of anhydrous guanine published to date, based on calculations performed at the highest theoretical level used so far for this type of systems.

\section{Acknowledgments}

The authors acknowledge financial support from the Portuguese Foundation for Science and Technology_PEst-OE/QUI/UI0070/2011. The Chemistry Department of the University of Aveiro 
(Portugal) is also acknowledged, for free access to the FT-Raman spectrometer. The INS work has been supported by the European Commission under the 7th Framework Programme through the Key Action: Strengthening the European Research Area, Research Infrastructures. Contract no. CP-CSA_INFRA2008-1.1.1 no. 226507-NMI3.

\section{References}

[1] M. Piacenza and S. Grimme, "Systematic quantum chemical study of DNA-base tautomers," Journal of Computational Chemistry, vol. 25, no. 1, pp. 83-99, 2004.

[2] W. Liang, H. Li, X. Hu, and S. Han, "Systematic theoretical investigations on all of the tautomers of guanine: from both dynamics and thermodynamics viewpoint," Chemical Physics, vol. 328, no. $1-3$, pp. 93-102, 2006.

[3] M. Y. Choi and R. E. Miller, "Four tautomers of isolated guanine from infrared laser spectroscopy in helium nanodroplets," Journal of the American Chemical Society, vol. 128, no. 22, pp. 73207328, 2006.

[4] J. Florián and V. Baumruk, "Scaled quantum mechanical force fields and vibrational spectra of solid-state nucleic acid constituents. 4. N7-protonated guanine," Journal of Physical Chemistry, vol. 96, no. 23, pp. 9283-9287, 1992.

[5] A. K. Chandra, M. T. Nguyen, T. Uchimaru, and T. Zeegers-Huyskens, "DFT study of the interaction between guanine and water," Journal of Molecular Structure, vol. 555, pp. 61-66, 2000.

[6] M. K. Shukla and J. Leszczynski, "Guanine in water solution: comprehensive study of hydration cage versus continuum solvation model," International Journal of Quantum Chemistry, vol. 110, no. 15 , pp. 3027-3039, 2010.

[7] U. Thewalt, C. E. Bugg, and R. E. Marsh, "The crystal structure of guanosine dihydrate and inosine dihydrate," Acta Crystallographica B, vol. 26, no. 8, pp. 1089-1101, 1970.

[8] J. Maixner and J. Zachova, "Redetermination of the structure of guanine hydrochloride monohydrate," Acta Crystallographica Section C, vol. 47, no. 11, pp. 2474-2476, 1991.

[9] K. Guille and W. Clegg, "Anhydrous guanine: a synchrotron study," Acta Crystallographica Section $C$, vol. 62, no. 8, pp. o515-0517, 2006.

[10] F. F. Maia, V. N. Freire, E. W. S. Caetano, D. L. Azevedo, F. A. M. Sales, and E. L. Albuquerque, "Anhydrous crystals of DNA bases are wide gap semiconductors," Journal of Chemical Physics, vol. 134, no. 17, Article ID 175101, 2011.

[11] J. M. Delabar and M. Majoube, "Infrared and Raman spectroscopic study of $15 \mathrm{~N}$ and D-substituted guanines," Spectrochimica Acta A, vol. 34, no. 2, pp. 129-140, 1978.

[12] C. Coulombeau, Z. Dhaouadi, M. Ghomi, H. Jobic, and J. Tomkinson, "Vibrational mode analysis of guanine by neutron inelastic scattering," European Biophysics Journal, vol. 19, no. 6, pp. $323-$ 326, 1991.

[13] M. Majoube, "Guanine residue: a normal-coordinate analysis of the vibrational spectra," Biopolymers, vol. 24, no. 6, pp. 1075-1087, 1984.

[14] R. Letellier, M. Ghomi, and E. Taillandier, "Out-of-plane vibration modes of nucleic acid bases. I. Pyrimidine bases," European Biophysics Journal, vol. 14, no. 4, pp. 227-241, 1987.

[15] M. Majoube, "Vibrational spectra of guanine. A normal coordinate analysis," Journal of Molecular Structure, vol. 114, pp. 403-406, 1984.

[16] M. P. Gaigeot, N. Leulliot, M. Ghomi, H. Jobic, C. Coulombeau, and O. Bouloussa, "Analysis of the structural and vibrational properties of RNA building blocks by means of neutron inelastic scattering and density functional theory calculations," Chemical Physics, vol. 261, no. 1-2, pp. 217-237, 2000. 
[17] Z. Dhaouadi, M. Ghomi, C. Coulombeau et al., "The molecular force field of guanine and its deuterated species as determined from neutron inelastic scattering and resonance Raman measurements," European Biophysics Journal, vol. 22, no. 3, pp. 225-236, 1993.

[18] J. Florián, "Scaled quantum mechanical force fields and vibrational spectra of solid-state nucleic acid constituents. 6. Guanine and guanine residue," Journal of Physical Chemistry, vol. 97, no. 41, pp. 10649-10658, 1993.

[19] B. Giese and D. McNaughton, "Density functional theoretical (DFT) and surface-enhanced Raman spectroscopic study of guanine and its alkylated derivatives: part 2: surface-enhanced Raman scattering on silver surfaces," Physical Chemistry Chemical Physics, vol. 4, no. 20, pp. 5171-5182, 2002.

[20] J. Duguid, V. A. Bloomfield, J. Benevides, and G. J. Thomas, "Raman spectroscopy of DNA-metal complexes. I. Interactions and conformational effects of the divalent cations: $\mathrm{Mg}, \mathrm{Ca}, \mathrm{Sr}, \mathrm{Ba}, \mathrm{Mn}$, Co, Ni, Cu, Pd, and Cd," Biophysical Journal, vol. 65, no. 5, pp. 1916-1928, 1993.

[21] C. M. Marian, "The guanine tautomer puzzle: quantum chemical investigation of ground and excited states," Journal of Physical Chemistry A, vol. 111, no. 8, pp. 1545-1553, 2007.

[22] Revision D.01 Gaussian 03, Gaussian, Inc., Wallingford, CT, USA, 2004.

[23] C. Lee, W. Yang, and R. G. Parr, "Development of the Colle-Salvetti correlation-energy formula into a functional of the electron density," Physical Review B, vol. 37, no. 2, pp. 785-789, 1988.

[24] A. D. Becke, "Density-functional exchange-energy approximation with correct asymptotic behavior," Physical Review A, vol. 38, no. 6, pp. 3098-3100, 1988.

[25] A. D. Becke, "Density-functional thermochemistry. III. The role of exact exchange," Journal of Chemical Physics, vol. 98, no. 7, pp. 5648-5652, 1993.

[26] G. A. Petersson, A. Bennett, T. G. Tensfeldt, M. A. Al-Laham, W. A. Shirley, and J. Mantzaris, "A complete basis set model chemistry. I. The total energies of closed-shell atoms and hydrides of the first-row elements," Journal of Chemical Physics, vol. 89, no. 4, pp. 2193-2218, 1988.

[27] C. Peng, P. Y. Ayala, H. B. Schlegel, and M. J. Frisch, "Using redundant internal coordinates to optimize equilibrium geometries and transition states," Journal of Computational Chemistry, vol. 17, no. 1, pp. 49-56, 1996.

[28] J. P. Merrick, D. Moran, and L. Radom, "An evaluation of harmonic vibrational frequency scale factors," Journal of Physical Chemistry A, vol. 111, no. 45, pp. 11683-11700, 2007.

[29] S. I. Gorelsky, University of Ottawa, Ottawa, Canada, 2010, http://www.sg-chem.net/.

[30] S. I. Gorelsky and A. B. P. Lever, "Electronic structure and spectra of ruthenium diimine complexes by density functional theory and INDO/S. Comparison of the two methods," Journal of Organometallic Chemistry, vol. 635, no. 1-2, pp. 187-196, 2001.

[31] A. J. Ramirez-Cuesta, "aCLIMAX 4.0.1, the new version of the software for analyzing and interpreting INS spectra," Computer Physics Communications, vol. 157, no. 3, pp. 226-238, 2004.

[32] J. P. Perdew and A. Zunger, "Self-interaction correction to density-functional approximations for many-electron systems," Physical Review B, vol. 23, no. 10, pp. 5048-5079, 1981.

[33] P. Giannozzi, S. Baroni, N. Bonini et al., "Quantum espresso: a modular and open-source software project for quantum simulations of materials," Journal of Physics Condensed Matter, vol. 21, no. 39, Article ID 395502, 2009.

[34] A. Dal Corso, S. Baroni, R. Resta, and S. De Gironcoli, "Ab initio calculation of phonon dispersions in II-VI semiconductors," Physical Review B, vol. 47, no. 7, pp. 3588-3592, 1993.

[35] N. Troullier and J. L. Martins, "Efficient pseudopotentials for plane-wave calculations," Physical Review B, vol. 43, no. 3, pp. 1993-2006, 1991.

[36] H. J. Monkhorst and J. D. Pack, "Special points for Brillouin-zone integrations," Physical Review $B$, vol. 13, no. 12, pp. 5188-5192, 1976.

[37] P. Gianozzi and S. Baroni, in Methods and Models, S. Yip, E. Kaxiras, N. Marzari, and B. Trout, Eds., vol. 1 of Handbook of MaterialsModeling, pp. 195-214, Springer, 2005. 
[38] B. Giese and D. McNaughton, "Density functional theoretical (DFT) and surface-enhanced Raman spectroscopic study of guanine and its alkylated derivatives: part 1. DFT calculations on neutral, protonated and deprotonated guanine," Physical Chemistry Chemical Physics, vol. 4, no. 20, pp. 5161-5170, 2002.

[39] J. Leszczyński, "Are the amino groups in the nucleic acid bases coplanar with the molecular rings? $\mathrm{Ab}$ initio HF/6-31G* and MP2/6-31G* studies," International Journal of Quantum Chemistry, vol. 44, supplement S19, pp. 43-55, 1992.

[40] J. Leszczynski, "The potential energy surface of guanine is not flat: an ab initio study with large basis sets and higher order electron correlation contributions," Journal of Physical Chemistry A, vol. 102, no. 13, pp. 2357-2362, 1998.

[41] J. Šponer and P. Hobza, "Nonplanar geometries of DNA bases. Ab initio second-order MøllerPlesset study," Journal of Physical Chemistry, vol. 98, no. 12, pp. 3161-3164, 1994.

[42] D. B. Jones, F. Wang, D. A. Winkler, and M. J. Brunger, "Orbital based electronic structural signatures of the guanine keto G-7H/G-9H tautomer pair as studied using dual space analysis," Biophysical Chemistry, vol. 125, no. 2-3, p. 560, 2007.

[43] P. S. Kushwaha, A. Kumar, and P. C. Mishra, "Electronic transitions of guanine tautomers, their stacked dimers, trimers and sodium complexes," Spectrochimica ActaA, vol. 60, no. 3, pp. 719-728, 2004.

[44] M. Shanmugasundaram and M. Puranik, "Computational prediction of vibrational spectra of normal and modified DNA nucleobases," Journal of Raman Spectroscopy, vol. 40, no. 12, pp. 1726-1748, 2009.

[45] L. Rao, H. Ke, G. Fu, X. Xu, and Y. Yan, "Performance of several density functional theory methods on describing hydrogen-bond interactions," Journal of Chemical Theory and Computation, vol. 5, no. 1, pp. 86-96, 2009.

[46] R. S. Fellers, D. Barsky, F. Gygi, and M. Colvin, "An ab initio study of DNA base pair hydrogen bonding: a comparison of plane-wave versus Gaussian-type function methods," Chemical Physics Letters, vol. 312, no. 5-6, pp. 548-555, 1999.

[47] M. Plazanet, N. Fukushima, and M. R. Johnson, "Modelling molecular vibrations in extended hydrogen-bonded networks - crystalline bases of RNA and DNA and the nucleosides," Chemical Physics, vol. 280, no. 1-2, pp. 53-70, 2002.

[48] A. M. Seuvre and M. Mathlouthi, "F.T.-I.R. spectra of oligo- and poly-nucleotides," Carbohydrate Research, vol. 169, pp. 83-103, 1987.

[49] M. Mathlouthi, A. M. Seuvre, and J. L. Koenig, "F.T.-I.R. and laser-raman spectra of guanine and guanosine," Carbohydrate Research, vol. 146, no. 1, pp. 15-27, 1986.

[50] R. Santamaria, E. Charro, A. Zacarías, and M. Castro, "Vibrational spectra of nucleic acid bases and their Watson-Crick pair complexes," Journal of Computational Chemistry, vol. 20, no. 5, pp. 511-530, 1999. 


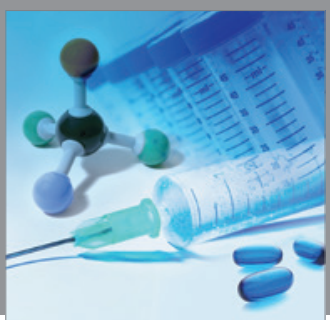

International Journal of

Medicinal Chemistry

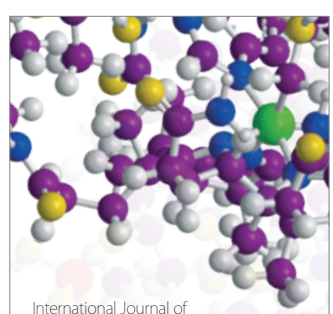

Carbohydrate Chemistry

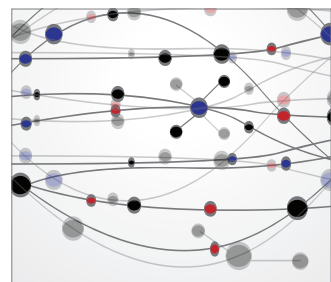

The Scientific World Journal
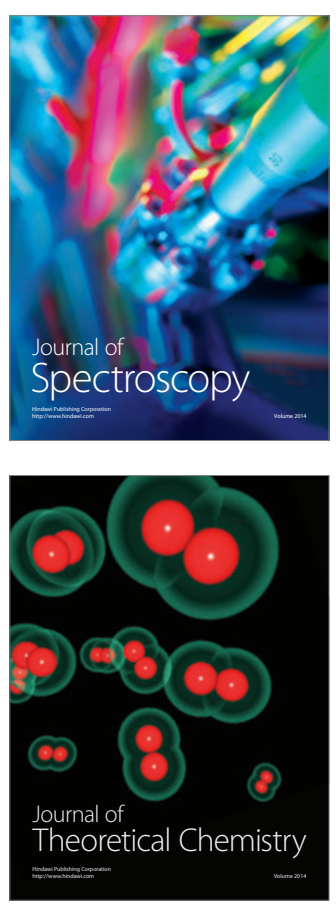
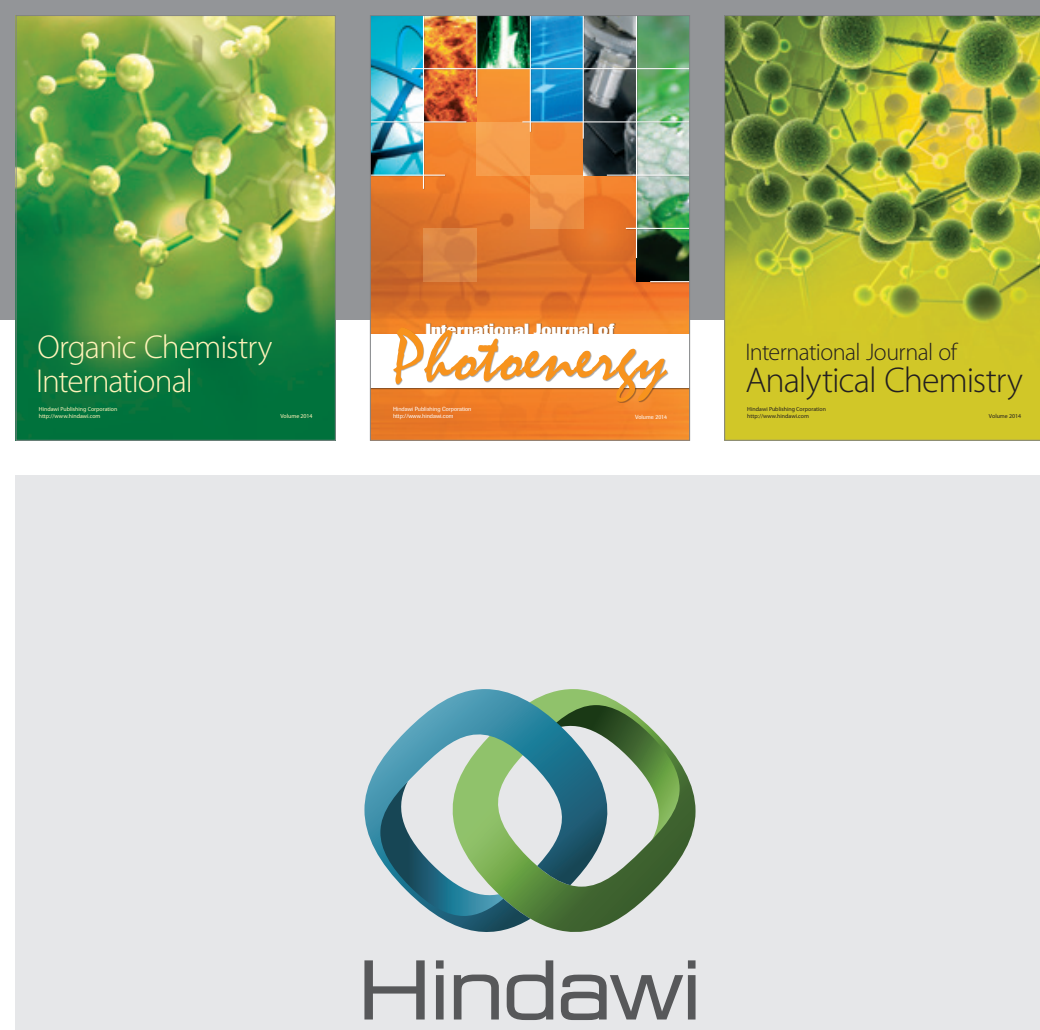

Submit your manuscripts at

http://www.hindawi.com
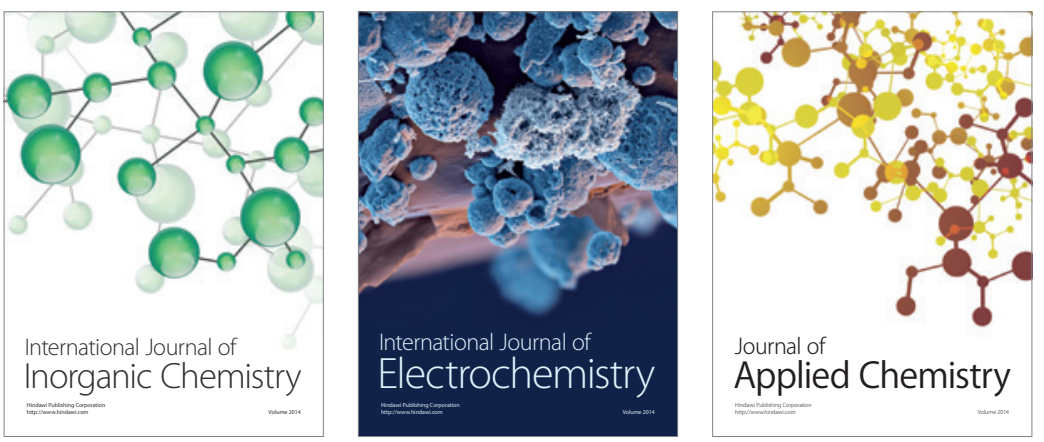

Journal of

Applied Chemistry
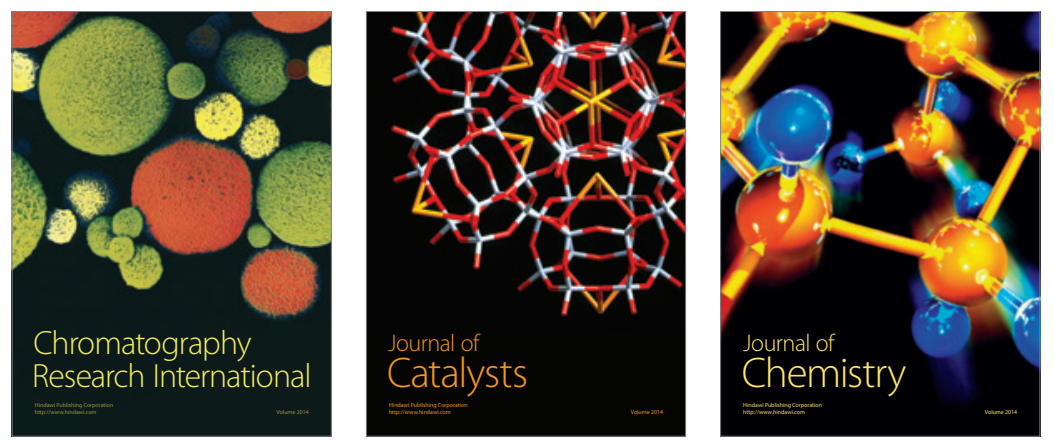
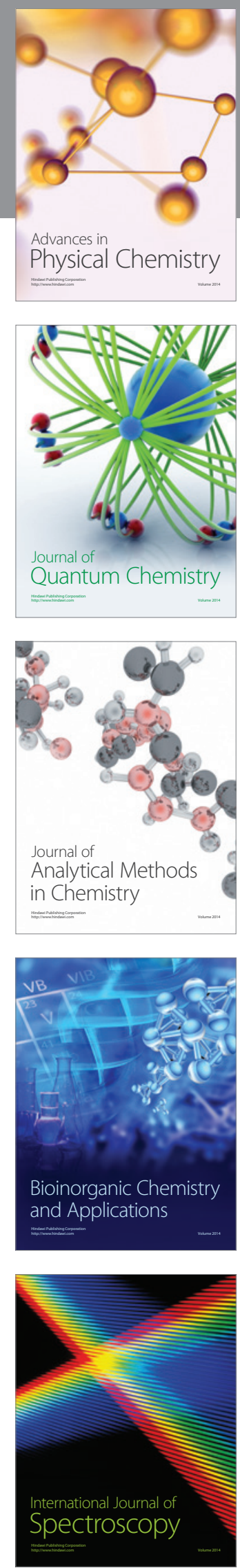